\title{
Chronic Subdural Hematoma Prognostic Factors for Recurrence
}

\author{
NAGEEB M. AL-SHAYA, M.Sc.; AHMAD A. KILANI, M.D.; AHMAD F. SHERIF, M.D. and \\ MOHAMMAD TAGHYAN, M.D.
}

The Department of Neurosurgy, Faculty of Medicine, Assiut University, Assiut, Egypt

\begin{abstract}
Background: Chronic Subdural Hematoma (CSDH) is a common neurologic disease in elderly. It is not always a benign condition because high recurrence rate had been reported. Independent risk factors for CSDH recurrence, especially the surgical and post-operative factors, had not been sufficiently investigated.
\end{abstract}

Aim of Study: To evaluate the outcome of CSDH after burr hole craniostomy and irrigation with closed system drainage, and to analyze the potential risk factors, emphasizing surgical and post-operative ones, for CSDH recurrence and comparing the results to others mentioned in literature.

Methods: We retrospectively analysed data of $82 \mathrm{CSDH}$ patients treated by burr hole(s) craniostomy and irrigation with close system drainage CSDH in Assuit University Hospital from July 2015 to July 2016.

Results: Of these CSDH patients, the main age was 58.9 years and $85.4 \%$ were males. The CSDH recurrence rate after burr-hole craniostomy was $7.3 \%$ in our hospital. CSDH recurrence was significantly associated with diabetes mellitus $(p=0.027)$, hypertension $(p=0.021)$ and prolonged PT ( $p=$ $0.025)$. Moreover an increased CSDH recurrence rate was observed in the patient group that had a mixed type $(p=0.047)$, separated $(p=0.044)$, trabecular $(p=0.025)$ and hematoma thickness more than $20 \mathrm{~mm}(p=0.34)$ of the CSDH in the preoperative diagnostic imaging .Also there were increased recurrence rate in patients group that had postoperative residual hematoma $(p<0.001)$.

Conclusion: We found diabetes mellitus, hypertension, prolonged PT, mixed type hematoma, separated, trabecular internal architecture of hematoma, thickness of hematoma $20 \mathrm{~mm}$ and post-operative residual hematoma independently predict recurrence of CSDH after burr hole(s) craniostomy. The patients with these risk factors may need closer surveillance post-operatively.

Key Words: Chronic subdural hematoma-Recurrence - Risk factor-Burrhole-Craniostomy.

Correspondence to: Dr. Nageeb M. Al-Shaya, The Department of Neurosurgy, Faculty of Medicine, Assiut University, Assiut, Egypt

\section{Introduction}

CHRONIC Subdural Hematoma (CSDH) represents an abnormal collection of liquefied blood degradation underneath the dura matter and usually forms in for approximately 3 weeks $[1,2]$. CSDH is one of the most frequent types of intracranial hemorrhage that is still associated with significant morbidity $[\mathbf{3 , 4}]$. The CSDH is a common disease in elderly patients, and its incidence is highest in persons older than 70 years of age [4]

Three principal techniques have been used for evacuation of CSDH: Burr hole with or without irrigation and with or without a closed drainage system, twist drill trephination and craniotomy. Burr-hole craniostomy with drainage appears to be the most effective treatments when considering morbidity, mortality and recurrence rate, burr hole drainage is relatively less invasive with high cure rate even for older or high risk patients [4-8]. However, some patients suffer from the recurrence after surgery, with an incidence as variable as 3.7 to $30 \%[\mathbf{1 , 4 , 9 - 1 2}]$.

Numerous factors influencing recurrence have been reported in the literature, but controversial findings are not uncommon. The recurrent rate has been showed to be influenced by multifactors such as pre-operative patient demographics, radiological type, thickness of hematoma and different surgical approach. Although numerous studies investigate these risk factors for CSDH the results have not been always consistent. So there are no established criteria of recurrence. Most studies focused on the pre-operative factors, but few concerned the surgical or post-operative factors, such as burr-hole numbers, use of drainage, duration and volume of drainage. This subject has not been studied sufficiently yet. 


\section{Patients and Methods}

This study is prospective randomizing hospitalbased clinical trial study included 82 patients whose diagnosed clinically and radiologically as CSDH and then underwent one or two burr holes procedure and irrigation with close system drainage at Neurosurgical Department of Assuit University Hospital from July 2015 to July 2016. This study included patients whose age were more than 18 years old and treated surgically. We were excluded patients who are treated conservatively or age less than 18 years old. The patient evaluated pre-operatively by detailed history, clinical examination, and laboratory investigations. Computerized Tomogram (CT) is the stander investigation where the thickness of hematoma was measured, also the type and internal architecture of the hematoma according to Nakaguchi et al., [13] ; that is homogenous, laminar, separated or trabecular was determined.

Under general endotracheal anesthesia. The patient positioned in supine position with the head slightly elevated $\left(15^{\circ}\right)$ and tilted to healthy side.

After scalp incision and burr hole/holes craniostomy was/were done the outer layer of dura cauterized by bipolar diathermy then we opened the dura in criss-cross manner with gradual evacuation of hematoma, then the margin of opened dura cauterized until shrunken completely to avoid bleeding from the opened dura to the subdural space, after that genital irrigation of hematoma by normal saline until complete evacuation of hematoma and the wash comes out clear then close system drainage with negative pressure was applied, subdurally or subgaleally. Finally the wound closed in layers. Patient admitted into the intensive care unit for 24 hours before referred to ward unless the patient deteriorated. The patient was given I.V antibiotic (usually fourth generation of cephalosporin like cefobid), antiepileptic and analgesic, in addition the patient was encouraged for fluid intake and I.V fluid for 24 hours. The patient was kept flat in bed without pillow 24 hours and allowed sitting and walking the next day. The drainage system was removed when drainage stopped mostly within 2-3 days. The patient discharged from hospital after 3-4 days and scalp stiches were removed 10 days post-operation. A recurrence of CSDH was defined as a subsequent increase in hematoma volume with fresh bleeding in the ipsilateral subdural space for which reoperation was performed, as described by Torihashi et al., [9]. The reoperation was performed to the patients having subsequent radiological increasing hematoma with reneurological deficits or no improvement of deficit.

\section{Outcomes assessment:}

\section{1- Clinical and radiological assessment:}

The Glasgow Coma Scale (GCS) and motor power were used to assist patient outcome. Also post-operative CT image was asked or requested within 24 hours if patient clinically deteriorated otherwise CT image was done within 48 to 72 hours post-operatively to detect any residual hematoma. Once the patient clinically and radiologically improved, discharged and followed-up in an outpatient clinic bases.

The patients were followed-up clinically and CT image at one month then clinically only at 3 and 6 months later.

\section{2- Prognostic factors that will be studied for re-} currence:

- Pre-operative prognostic factors:

- Age of patient.

- Associated chronic diseases like hypertension, diabetes mellitus, liver diseases and renal impairment.

- Laboratory investigation like $\mathrm{Hb}$, platlate count, $\mathrm{PC}$, and $\mathrm{PT}$.

- Pre-oprative radiological parameters:

A- Hematoma thickness: Less than $10 \mathrm{~mm}$, from $10 \mathrm{~mm}$ to $20 \mathrm{~mm}$ or more than $20 \mathrm{~mm}$.

$B$-Density of hematoma: Hypodense, hyperdense, isodense or mixed.

C- Internal architecture of CSDH according to Nakaguchi et al.

- Operative prognostic factors:

- Number of burr hole: One or two burr holes.

- Position of drain: Subgaleal or subdural.

-Post-operative risk factors:

- Duration of drainage: Equal or less (<2), and (3-5) days.

- Amount of drainage: <100, (100-200), (200$300)$, and $300<$.

- Present of post-operative residual hematoma.

Statistical analysis:

The data were tested for normality using the Anderson-Darling test and for homogeneity vari- 
ances prior to further statistical analysis. Categorical variables were described by number and percent $(\mathrm{N}, \%)$, where continuous variables described by mean and standard deviation (mean, SD). Chisquare test and fisher exact test used to compare between categorical variables. Multiple logistic regression analysis used to assess the predictors of recurrence. A two-tailed $p<0.05$ was considered statistically significant. All analyses were performed with the IBM SPSS 20.0 software.

\section{Results}

This study included 82 patients, 70 patients $(85.4 \%)$ were males and 12 patients $(24.6 \%)$ were females. The mean age was 58.9 years (range 3493 years). Among all patients about 20 patients (24.4\%) had diabetes mellitus, 28 patients $(34.1 \%)$ had hypertension and 4 patients $(4.9 \%)$ had chronic liver disease. Thirty patients were presented with disturbed conscious level (GCS range of the patient was [9-14]). Regarding motor power about 30 patients had full motor power and the others had some sort of motor weakness. Six patients $(7.3 \%)$ had Prothrombin Time (PT) more than 14 seconds (control value 11.5-12 seconds) while the Prothrombin Concentration (PC) was less than $70 \%$ in 6 patients $(7.3 \%)$, also $\mathrm{Hb}$ level was less than $10 \mathrm{mg} / \mathrm{dl}$ in 6 patients $(7.3 \%)$. Pre-operative CT scan evaluation of patient's hematoma density demonstrated that 14 patients $(17.1 \%)$ had hypodense, 38 patients $(46.3 \%)$ had isodense, 4 patients $(4.9 \%)$ had hyperdense and 26 patients (3 1.7\%) had mixed type. Regarding radiological internal architecture of hematoma, 42 patients $(51.2 \%)$ had homogenous hematoma, 14 patients $(17.1 \%)$ had laminar hematoma, 10 patients $(12.2 \%)$ had separated hematoma and 16 patients $(19.5 \%)$ had trabecular hematoma. Fourteen patients $(17.1 \%)$ had hematoma thickness between $(10-20 \mathrm{~mm})$ while 68 patients $(82.9 \%)$ had hematoma thickness more than $20 \mathrm{~mm}$. Out of all patients who operated, 10 patients $(12.2 \%)$ underwent one burr hole while 72 of patients $(87.8 \%)$ underwent two burr holes. The drain was placed subglial $(\mathrm{Sg})$ in 62 patients $(75.6 \%)$ while drain was placed subdural $(\mathrm{Sd})$ in 20 patients $(24.4 \%)$. The amount of drainage that accumulated post-operative in the drainage system was less than $100 \mathrm{ml}$ in 2 patients $(2.4 \%),(100-200 \mathrm{ml})$ in 36 patients $(43.9 \%),(200-$ $300 \mathrm{ml}$ ) in 32 patients $(39 \%)$, and more than $300 \mathrm{ml}$ in 12 patients $(14.6 \%)$. Also the drain maintained or kept in situ less than 3days in 28 patients (34.1\%) and (3-5) days in 54 patients (65.9\%). Follow-up brain CT within 48 hours post-operatively demonstrated that 12 patients $(14.6 \%)$ had residual hematoma. These patients managed conservatively and not needed to early re-evacuation. During the early follow-up, that's one month after surgery; six patients presented with recurrence of CSDH as follow: One patient $(16.7 \%)$ within the first week, two patients $(33.3 \%)$ within the second week, two patients $(33.3 \%)$ within the third week, and the last one $(16.7 \%)$ between the fourth and fifth week. All these patients underwent reevacuation with good outcome. The recurrence rate in all our study was $7.3 \%$ as shown in (Table $1)$.

All patients with recurrence of CSDH were above 60 years old but they are not statistically significant $(p=0.246)$. Diabetes and hypertension were statistically significant factors regarding recurrence of CSDH; 4 out of 6 recurrent patients were diabetic $(66.7 \%)$ with $(p=0.027)$ while 6 out of 6 recurrent patients were hypertensive $(100 \%)$ with $(p=0.021)$ as shown in (Table 2). There is no relationship between recurrent CSDH and patients had chronic liver disease $(p=0.889)$. Among recurrence patient, about 2 patients $(33.3 \%)$ had prothrombin time more than 14 seconds (control 11.512 second) with significant correlation with recurrence $(p=0.025)$, while prothrombin concentration more than $70 \%$ is protective factor of recurrence CSDH $(p=0.029)$ as shown in (Table 3). The recurrence occurred in 4 patients $(66.7 \%)$ with mixed type of hematoma which was statistically significant $(p=0.047)$ while others types were statistically insignificant for recurrence. The statistically significant recurrence occurred in 2 patients $(33.3 \%)$ and 4 patients $(66.7 \%)$ with both separated and trabecular hematoma respectively with the $p$ value was $(p=0.044)$ and $(p=0.025)$ respectively while there were no recurrence among others. All six patients displayed recurrence had radiological hematoma thickness more than $20 \mathrm{~mm}$ and was statistically significant $(p=0.034)$ (Table 4$)$. The recurrence of CSDH occurred exclusively among patients underwent two burr holes $n=6(100 \%)$ and also recurrence was more among patients with subgalial (Sg) drain $n=4$ out of $6(66.7 \%)$ in comparison with patients with subdural $(\mathrm{Sd})$ drain but that was statistically insignificant where $p$-value was $(p=0.633)$ and $(p=0.599)$ respectively. Although recurrence was exclusively among patients in whom the drain maintained 3 days or more but it is statistically insignificant $(p=0.52)$. Also there were no correlation between recurrence and amount of drainage $(p>0.596)$. Out of all patients of recurrence about 4 patients $(66.7 \%)$ had post-operative residual hematoma and was statistically significant ( $p$ $<0.001$ ) (Table 5). 
Table (1): Frequency distribution of studied patient's risk factors.

\begin{tabular}{|c|c|c|c|c|c|c|c|c|}
\hline & No & $\%$ & & No. & $\%$ & & No. & $\%$ \\
\hline Age: & & & $H b:$ & & & Thickness of & & \\
\hline$<40$ & 4 & 4.9 & $<10$ & 6 & 7.3 & hematoma: & & \\
\hline $40-50$ & 8 & 9.8 & $>10$ & 76 & 92.7 & $1-2 \mathrm{~cm}$ & 14 & 17.1 \\
\hline $50-60$ & 20 & 24.4 & LFT: & & & $>2 \mathrm{~cm}$ & 68 & 82.9 \\
\hline $\begin{array}{l}>60 \\
\text { Range }\end{array}$ & 50 & 61.0 & Normal & 82 & 100.0 & No. of burrhole: & & \\
\hline Mean \pm SD & & 2.4 & KFT: & & & One & 10 & 12.2 \\
\hline Kidney disease: & & & Normal & 80 & 97.6 & Two & 72 & 87.8 \\
\hline Absent & 82 & 100.0 & $\begin{array}{l}\text { Abnormal } \\
P T \text {. }\end{array}$ & 2 & 2.4 & $\begin{array}{l}\text { Position of drain: } \\
\quad \mathrm{Sg}\end{array}$ & 62 & 75.6 \\
\hline $\begin{array}{l}\text { DM: } \\
\quad \text { Present }\end{array}$ & & & $\begin{array}{l}P T: \\
\quad 10-12\end{array}$ & 34 & 41.5 & $\mathrm{Sd}$ & 20 & 24.4 \\
\hline $\begin{array}{l}\text { Present } \\
\text { Absent }\end{array}$ & $\begin{array}{l}20 \\
62\end{array}$ & $\begin{array}{l}24.4 \\
75.6\end{array}$ & $>12-14$ & 42 & 51.2 & Duration of drain: & & \\
\hline Absent & 62 & 15.6 & $>14-16$ & 4 & 4.9 & Less than 3 days & 28 & 34.1 \\
\hline$H T N:$ & & & $>16$ & 2 & 2.4 & 3 days and more & 54 & 65.9 \\
\hline Present & $\begin{array}{l}28 \\
54\end{array}$ & 34.1 & $P C:$ & & & Amount of draining: & & \\
\hline Absent & 54 & DM & $<70 \%$ & 6 & 7.3 & $<100$ & 2 & 2.4 \\
\hline Liver disease: & & & $>70 \%$ & 76 & 92.7 & $100-<200$ & 36 & 43.9 \\
\hline Present & 4 & 4.9 & & & & $200-<300$ & 32 & 39.0 \\
\hline Absent & 78 & 95.1 & $100-150$ & 4 & 4.9 & $300-400$ & 12 & 14.6 \\
\hline$G C S:$ & \multirow{2}{*}{\multicolumn{2}{|c|}{$9-15$}} & $>150$ & 78 & 95.1 & Post-operative residual & & \\
\hline Range & & & Hematoma radiological type: & & & hematoma: & & \\
\hline Mean \pm SD & \multicolumn{2}{|c|}{$14.3 \pm 1.3$} & $\begin{array}{l}\text { Hematoma radiological type: } \\
\text { Hypodense }\end{array}$ & 14 & 17.1 & Present & 12 & 14.6 \\
\hline Power: & & & Isodense & 38 & 46.3 & Absent & & \\
\hline 5 & 30 & 36.6 & Hyperdense & 4 & 4.9 & Recurrence: & & \\
\hline 4 & 30 & 36.6 & Mixed & 26 & 31.7 & Yes & 6 & 7.3 \\
\hline 3 & 10 & 12.2 & Hematoma architecture: & & & No & 76 & 92.7 \\
\hline 1 & 2 & 2.4 & $\begin{array}{l}\text { Hematoma architecture: } \\
\text { Homogenous }\end{array}$ & 42 & 51.2 & & & \\
\hline 0 & 10 & 12.2 & Laminar & 14 & 17.1 & & & \\
\hline Sensation: & & & Separated & 10 & 12.2 & & & \\
\hline Intact & 82 & 100.0 & Trabecular & 16 & 19.5 & & & \\
\hline
\end{tabular}

Table (2): Multivariate analysis to determine the most historical risk factors of recurrence.
Table (3): Multivariate analysis to determine the most laboratory risk factors of recurrence.

\begin{tabular}{|c|c|c|c|c|c|c|c|c|c|c|c|c|}
\hline & \multicolumn{4}{|c|}{ Recurrence } & \multirow{3}{*}{$\begin{array}{c}p- \\
\text { value }\end{array}$} & & \multicolumn{4}{|c|}{ Recurrence } & \multirow{3}{*}{$\begin{array}{c}\text { Odds } \\
(95 \% \mathrm{CI})\end{array}$} & \multirow{3}{*}{$\begin{array}{c}p- \\
\text { value }\end{array}$} \\
\hline & \multicolumn{2}{|c|}{ Yes } & \multicolumn{2}{|c|}{ No } & & & \multicolumn{2}{|c|}{ Yes } & \multicolumn{2}{|c|}{ No } & & \\
\hline & No. & $\%$ & No. & $\%$ & & & No. & & No. & & & \\
\hline Age: & & & & & & $H B:$ & & & & & & \\
\hline$<40$ & 0 & 0.0 & 2 & 5.3 & 0.558 & $<10$ & 6 & 7.9 & 0 & 0.0 & 1 (reference) & \\
\hline $40-50$ & 0 & 0.0 & 4 & 10.5 & & $>10$ & 70 & 92.1 & 6 & 100.0 & $1.2(0.1-23.7)$ & 0.905 \\
\hline $50-60$ & 0 & 0.0 & 10 & 26.3 & & $K F T:$ & & & & & & \\
\hline$>60$ & 3 & 100.0 & 22 & 57.9 & & $\begin{array}{l}\text { Normal } \\
\text { Abnormal }\end{array}$ & $\begin{array}{l}74 \\
2\end{array}$ & $\begin{array}{l}97.4 \\
2.6\end{array}$ & $\begin{array}{l}6 \\
0\end{array}$ & $\begin{array}{l}100.0 \\
0.0\end{array}$ & $\begin{array}{l}1 \text { (reference) } \\
2.3(0.1-52.9)\end{array}$ & 0.605 \\
\hline$D M:$ & & & & & & $P T:$ & & & & & & \\
\hline Yes & 2 & 66.7 & 8 & 21.1 & 0.077 & $10-$ & 32 & 42.1 & 2 & 33.3 & 1 (reference) & \\
\hline No & 1 & 33.3 & 30 & 78.9 & & $\begin{array}{l}12- \\
14-\end{array}$ & $\begin{array}{l}40 \\
2\end{array}$ & $\begin{array}{l}52.6 \\
2.6\end{array}$ & $\begin{array}{l}2 \\
2\end{array}$ & $\begin{array}{l}33.3 \\
33.3\end{array}$ & $\begin{array}{l}0.8(0.1-6.0) \\
16(1.4-180.9)\end{array}$ & $\begin{array}{l}0.828 \\
0.025^{*}\end{array}$ \\
\hline$H T N:$ & & & & & & $16-$ & 2 & 2.6 & 0 & 0.0 & $2.6(0.1-70.3)$ & 0.570 \\
\hline Yes & 3 & 100.0 & 11 & 28.9 & $0.012^{*}$ & $P C:$ & & & & & & \\
\hline No & 0 & 0.0 & 27 & 71.1 & & $\begin{array}{l}<70 \% \\
>70 \%\end{array}$ & $\begin{array}{l}4 \\
72\end{array}$ & $\begin{array}{l}5.3 \\
94.7\end{array}$ & $\begin{array}{l}2 \\
4\end{array}$ & $\begin{array}{l}33.3 \\
66.7\end{array}$ & $\begin{array}{l}1 \text { (reference) } \\
0.11(0.02-0.79)\end{array}$ & $0.029 *$ \\
\hline $\begin{array}{l}\text { Liver disease: } \\
\quad \text { Yes }\end{array}$ & 0 & 0.0 & 2 & 5.3 & 0.684 & $\begin{array}{l}\text { Platelet: } \\
100-150\end{array}$ & 4 & 5.3 & 0 & 0.0 & 1 (reference) & \\
\hline No & 3 & 100.0 & 36 & 94.7 & & $>150$ & 72 & 94.7 & 6 & 100.0 & $0.8(0.04-16.7)$ & 0.889 \\
\hline
\end{tabular}


Table (4): Multivariate analysis to determine the most radiological risk factors of recurrence.

\begin{tabular}{|c|c|c|c|c|c|c|}
\hline & \multicolumn{4}{|c|}{ Recurrence } & \multirow{3}{*}{$\begin{array}{l}\text { Odds } \\
(95 \% \mathrm{CI})\end{array}$} & \multirow{3}{*}{$\begin{array}{c}p- \\
\text { value }\end{array}$} \\
\hline & \multicolumn{2}{|c|}{ No } & \multicolumn{2}{|c|}{ Yes } & & \\
\hline & No. & $\%$ & No. & $\%$ & & \\
\hline \multicolumn{7}{|l|}{ Type of } \\
\hline $\begin{array}{l}\text { hematoma: } \\
\text { Hypodense }\end{array}$ & 14 & 18.4 & 0 & 0.0 & 1 (reference) & 0.461 \\
\hline Isodense & 36 & 47.4 & 2 & 33.3 & $2(0.1-3.2)$ & 0.664 \\
\hline Hyperdense & 4 & 5.3 & 0 & 0.0 & - & \\
\hline Mixed & 22 & 28.9 & 4 & 66.7 & $5.8(1.1-28.8)$ & $0.047 *$ \\
\hline \multicolumn{7}{|c|}{$\begin{array}{l}\text { Radiological } \\
\text { architecture: }\end{array}$} \\
\hline Homogenous & 42 & 55.3 & 0 & 0.0 & 1 (reference) & 0.069 \\
\hline Laminar & 14 & 18.4 & 0 & 0.0 & - & \\
\hline Separated & 8 & 10.5 & 2 & 33.3 & $5(1.2-9.8)$ & $0.044 *$ \\
\hline Trabecular & 12 & 15.8 & 4 & 66.7 & $7.2(1.5-15.3)$ & $0.025^{*}$ \\
\hline \multicolumn{7}{|l|}{$\begin{array}{l}\text { Thickness of } \\
\text { hematoma: }\end{array}$} \\
\hline $10-20 \mathrm{~mm}$ & 14 & 18.4 & 0 & 0.0 & 1 (reference) & \\
\hline$>20 \mathrm{~mm}$ & 62 & 81.6 & 6 & 100.0 & $3(1.2-56.2)$ & $0.034 *$ \\
\hline
\end{tabular}

Table (5): Multivariate analysis to determine the most operative and post-operative risk factors of recurrence.

\begin{tabular}{|c|c|c|c|c|c|c|}
\hline & \multicolumn{4}{|c|}{ Recurrence } & \multirow{3}{*}{$\begin{array}{c}\text { Odds } \\
\text { (95\%CI) }\end{array}$} & \multirow{3}{*}{$\begin{array}{c}p- \\
\text { value }\end{array}$} \\
\hline & \multicolumn{2}{|c|}{ No } & \multicolumn{2}{|c|}{ Yes } & & \\
\hline & No. & $\%$ & No. & $\%$ & & \\
\hline \multicolumn{7}{|l|}{ No. of burrhole: } \\
\hline • One & 10 & 13.2 & 0 & 0.0 & 1 (reference) & \\
\hline • Two & 66 & 86.8 & 6 & 100.0 & $2.1(0.2-39.2)$ & 0.633 \\
\hline \multicolumn{7}{|c|}{ Position ofdrain: } \\
\hline - SC & 58 & 76.3 & 4 & 66.7 & 1 (reference) & \\
\hline - SD & 18 & 23.7 & 2 & 33.3 & $1.6(0.3-9.5)$ & 0.599 \\
\hline \multicolumn{7}{|l|}{$\begin{array}{l}\text { Duration of } \\
\text { drain: }\end{array}$} \\
\hline $\begin{array}{l}\text { - Less than } \\
3 \text { davs }\end{array}$ & 28 & 36.8 & 0 & 0.0 & 1 (reference) & \multirow{2}{*}{$0.022 *$} \\
\hline $\begin{array}{l}\text { - } 3 \text { days and } \\
\text { more }\end{array}$ & 48 & 63.2 & 6 & 100.0 & $7.6(1.4-14.7)$ & \\
\hline \multicolumn{7}{|l|}{$\begin{array}{l}\text { Amount of } \\
\text { draining: }\end{array}$} \\
\hline$\bullet<100$ & 2 & 2.6 & 0 & 0.0 & 1 (reference) & \\
\hline • $100-200$ & 32 & 42.1 & 4 & 66.7 & $0.7(0.03-16.8)$ & 0.821 \\
\hline • 200-300 & 30 & 39.5 & 2 & 33.3 & $0.4(0.02-11.1)$ & 0.596 \\
\hline • $300-400$ & 12 & 15.8 & 0 & 0.0 & & - \\
\hline \multicolumn{7}{|l|}{$\begin{array}{l}\text { Post-operative } \\
\text { residual } \\
\text { hematoma: }\end{array}$} \\
\hline • Present & 68 & 89.5 & 2 & 33.3 & 1 (reference) & \multirow{2}{*}{$\begin{array}{l}<0.001 \\
* *\end{array}$} \\
\hline -Absent & 8 & 10.5 & 4 & 66.7 & $17(2.7-10.3)$ & \\
\hline
\end{tabular}

\section{Discussion}

$\mathrm{CSDH}$ is a common disease in neurosurgical practice and the incidence is increasing [14], usually it does require repeated surgical treatment. There is not a standard consensus about the surgical treatment method. For the last twenty years, the most frequently used surgical techniques have been burr-hole drainage, irrigation and closed drainage. However it has been reported that recurrence rate range from 3.7 to $30 \%$ [1,4,9-12]. This study showed a recurrence rate of $7.3 \%$.

The etiology of recurrence of CSDH has not been completely understood until now [15], but several risk factors for recurrence of CSDH have been reported, including advanced age, brain atrophy, bilateral CSDH, hematoma density, seizures, diabetes mellitus, bleeding tendency, alcohol abuse, and post-operative posture [9,13,16-19]. However, the definitive risk factors have not been defined until now. The purpose of this study was to evaluate and identify the risk factors for recurrence of CSDH whether pre-operative like age, liver disease, diabetes mellitus, hypertension, prothrombin time, radiological density, internal architecture and thickness of hematoma, operative like number of burr hole and position of drain and post-operative ones like amount of drainage, duration of drain and residual hematoma.

The literature states that the risk of CSDH recurrence increases with age. This may be correlated to brain atrophy and decayed of cerebral veins. In our study, no significant difference was observed between the average ages of the patients and the incidence of recurrence and non-recurrent. These results are consistent with those of Lee et al. [8], Nordmann et al., [20], Stanistic et al., [21], Abouzari et al., [22] and Weigel et al., [23] .

In our study, no significant difference was observed between the incidence of recurrence of CSDH among patients with liver disease and those who had no liver disease, this may be explained that they had inactive chronic hepatitis and liver is not in cirrhotic stage. On the contrary patients in Gronbaek et al., [24], Kaul et al., [25] and MaCormick et al., [26] studies were in cirrhotic stage of liver disease and this was associated with increased risk of recurrence.

Also in this study prolonged prothrombin time was correlated with increase recurrence of CSDH due to deficiency of clotting factors (I, II, V, VII, and $\mathrm{X}$ ) made by the liver.

In our study hypertension was a risk factor of recurrence, it may cause damage to blood vessels specially in elderly patients whose blood vessels were sclerotic and lost their elasticity so these vessels become more liable to rupture, in contrary to the study of Torihashi et al., [9] which showed that hypertension did not have any effect on recurrence. 
Regarding diabetes Torihashi et al., [9]: Speculated that viscosity increases in diabetic patients, an osmotic pressure increase will trigger coagulation and decrease the risk of hematoma; however, they could not determine diabetes as an effective factor in their studies [9]. Tugcu et al., found there was no association between diabetes and CSDH recurrence [27]. In our study, diabetes was a significant risk factor of recurrence of $\mathrm{CSDH}$, which may be correlated to capillary vasculopathy, particularly in patients with CSDH, where there is a sufficient capillary network on the outer membrane and the vasculopathy here may lead to a growth or recurrence of the hematoma.

Regarding CT hematoma density, Ko et al., and Kong et al.: Found that, the incidence of CSDH recurrence in the high-density and mixed-density groups was significantly higher than that in the low-density and iso-density groups $[4,11]$ and this agreed with our study where the incidence of CSDH recurrence in the mixed-density group was significantly higher than other groups.

Regarding the internal architecture of CSDH: Separated stage of CSDH consider as a significant risk factor of CSDH in many reports $[\mathbf{1 0 , 2 1 , 2 8 - 3 0}]$ while others stated laminar stage of CSDH was risk factor of recurrence [1] and homogenous stage had a lowest recurrence rate in all previous reports. In this study we found both separated and trabecular hematomas were risk factors of recurrence, due to hyperfibrinolysis and the rebleeding from the neomembrane (the blood vessels of neomembrane is premature and friable) is high, so operation for evacuation of CSDH is preferable to do in homogenous stage to decrease incidence of recurrence unless sever symptom are present.

Many authors stated that hematoma thickness $>20 \mathrm{~mm}$ was significant risk factor of recurrence CSDH $[1,5,11,21,31]$ the pathogenesis is unknown but it has been stated that any factor leading to a prolonged post-operative widening of the hematoma cavity (brain atrophy, residual hematoma, massive subdural air collection, excessive fluid drainage through subdurally placed drains) may cause an impaired adhesion between the inner and outer hematoma neomembranes and thus facilitate post-

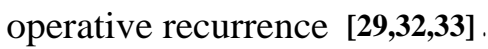

Few studies have been done to compare directly the use of one and two burr-hole techniques for the surgical management of chronic subdural hematoma. Despite this, both techniques are widely used by neurosurgeons [34], and no consensus has been reached whether one technique is superior to the other.
Han et al., [35], Kansal et al., [36], Belkhair et al., [37] reported no significant difference in recurrence rate observed between $2 \mathrm{BHC}$ (two burr holes craniostomy) and 1 BHC (one burr hole craniostomy), but Taussky et al., [38] : Reported a significantly higher rate of recurrence was found for $1 \mathrm{BHC}$ compared to $2 \mathrm{BHC}$. In our study, recurrence rate was more in patient underwent to $2 \mathrm{BHC}$ but that was statistically insignificant.

We could not found studies investigated directly the comparison between subdural with subgaleal drainage and incidence of recurrence of CSDH. Although some reported that the recurrence rate has been low by using subdural (Sd) drainage [3941], there is still disagreement on whether subdural drainage should be performed post-operatively [15,42-44]. Placement of a subgaleal $(\mathrm{Sg})$ drain after a craniotomy has been reported with a low recurrence rate in the thesis of Gazzeri et al., and Mohamed et al., $[45,46]$. In this study although recurrence rate was more in patients with subgalial $(\mathrm{Sg})$ drainage in comparing with patients with subdural (Sd) drainage but that was statistically insignificant.

Regarding the relationship between volume of drainage and recurrence rate: Kwon et al., [47], reported a correlation between postoperative drainage volume with the recurrence rate. When the total drainage volume was below $200 \mathrm{ml}$, the recurrence rate increased from $0 \%$ to $6.4 \%$, while Cheng et al., [1], found that larger drainage amount is independently associated with higher recurrence rate of CSDH. They suggested some explanations. First, some CSDH with large post-operative drainage amount may be transformed from subdural hygroma, notably it has been reported that persistent subdural hygroma is an important risk factor in the development of CSDH. Second, some elderly patients had severe cerebral atrophy and poor brain re-expansion, after hematoma evacuation, cerebrospinal fluid may pass through into the low-pressure subdural space. If there is large amount of subdural effusion, the bridge veins in the subdural space may tear gradually and bleeding from the inner membrane or more anti-thrombolytic factors produced made the CSDH recurrent. However, Stanisic et al., [21], reported there was no correlation between post-operative drainage volume with the recurrence rate, which correlate with our results where no relationship between recurrence rate and volume of drainage.

Stanisic et al., [21], reported that the appearance of acute subdural clots in cranial base CSDHs on CT scans obtained within four days postsurgery had a higher recurrence rate than that with absence 
of these clots. Benzel et al., [42] suggested recurrence rate depends on the removal of the residual semisolid subdural hematoma component and the removal, dilution and inactivation of endogenous fibrinolytic agents and refilling the subdural cavity with saline prevent the influx of air into the subdural space and this reduce the recurrence rate of CSDH [12].

In our study, the recurrence was significant in patients with post-operative residual hematoma following-up by brain CT 24 to 48 hours and within 3 weeks after surgery, so it is important to remove solid or semi-solid hematoma either by continuous irrigation or craniectomy.

\section{Conclusion:}

$\mathrm{CSDH}$ is common neurosurgical problems and a recurrent rate after surgical treatment is not uncommon. Certain risk factors influencing postoperative recurrence of CSDH were articulated in our study. Hypertension, DM, prolong PT, mixed density, separated and trabecular internal architecture of hematoma, and the thickness of hematoma more than $20 \mathrm{~mm}$ in pre-operative CT and postoperative residual hematoma. However no correlation between age of patient, inactive chronic liver disease, number of burr hole, position of drain and amount of drainage with recurrence of $\mathrm{CSDH}$.

This information might be helpful for determining patients with high incidence of recurrence for close follow-up and acts to reduce the recurrence such as evacuation of hematoma that is doing at homogenous stage and complete evacuation of hematoma may reduce the incidence of recurrence.

\section{References}

1- CHENG C., et al.: Radiological Features and PostOperative Drainage Amount Independently Predict Recurrence of Chronic Subdural Hematoma after Burr-hole. J. Neurol. Disord., 2: 2-5, 2014.

2- LEE J.M., PARK J.C. and KIM J.H.: Retrospective Analysis of Risk Factors for Recurrent Chronic Subdural Hematoma. The Nerve, 2: 54-8, 2016.

3- ISHI M.O., OYAMA M.T., AMATANI S.T., ITAZAWA T.K. and AITO M.S.: Clinical Factors of Recurrent Chronic Subdural Hematoma. Neurol. Med. Chir., 382-6, 2001.

4- KO B.S., et al.: Clinical analysis of risk factors related to recurrent chronic subdural hematoma. J. Korean Neurosurg. Soc., 43: 11-5, 2008.

5- K.H.C. J.M.L. and E.J.K.: Independent predictors for recurrence of chronic subdural hematoma. Acta Neurochir. (Wien)., 154: 1541-8, 2012

6- SOUSA E.B., BRANDÃO L.F.S., TAVARES C.B., BORGES I.B. C. and NETO N.G.F.: Epidemiological characteristics of 778 patients who underwent surgical drainage of chronic subdural hematomas in Brasília, Brazil, 2013.

7- WEIGEL R., SCHMIEDEK P. and KRAUSS J.K.: Outcome of contemporary surgery for chronic subdural haematoma: Evidence based review. J. Neurol. Neurosurg. \& Psychiatry, 937-43, 2003.

8- LEE J., EBEL H., ERNESTUS R. and KLUG N.: Various Surgical Treatments of Chronic Subdural Hematoma and Outcome in 172 Patients: Is Membranectomy Necessary? Surg. Neurol., 61: 523-7, 2004.

9- TORIHASHI K., et al.: Independent predictors for recurrence of chronic subdural hematoma: A review of 343 consecutive surgical cases. Neurosurgery, 63: 1125-9, 2008.

10- OHBA S., KINOSHITA Y. and NAKAGAWA T.: The risk factors for recurrence of chronic subdural hematoma. Neurosurg. Rev., 36: 145-50, 2013.

11- KONG W., KIM B., CHO K. and HONG S.: Factors Affecting Post-operative Recurrence of Chronic Subdural Hematoma. Korean J. Neurotrauma, 8: 122-7, 2012.

12- EROL F.S., TOPSAKAL C., FAIK OZVEREN M., KAPLAN M. and TIFTIKCI M.T. : Irrigation vs. closed drainage in the treatment of chronic subdural hematoma. J. Clin. Neurosci., 12: 261-3, 2005.

13- NAKAGUCHI H., TANISHIMA T. and YOSHIMASU N.: Factors in the natural history of chronic subdural hematomas that influence their post-operative recurrence. J. Neurosurg., 95: 256-62, 2001.

14- VAN DER VEKEN J., et al.: Mini-craniotomy as the primary surgical intervention for the treatment of chronic subdural hematoma: A retrospective analysis. Acta Neurochir. (Wien), 156: 981-7, 2014.

15- MARKWALDER T.: Chronic subdural hematomas" a review. J. Neurosurg., 54: 637-45, 1981.

16- FUKUHARA T., GOTOH M., ASARI S., OHMOTO T. and AKIOKA T.: The relationship between brain surface elastance and brain re-expansion after evacuation of chronic subdural hematoma. Surg. Neurol., 45: 570-4, 1996.

17- MORI K. and MAEDA M.: Surgical treatment of chronic subdural hematoma in 500 consecutive cases: Clinical characteristics, surgical outcome, complications, and recurrence rate. Neurol. Med. Chir. (Tokyo), 41: 371-81, 2001.

18- OISHI M., TOYAMA M. and CROSSHOSPITAL R.: Chir (Tokyo) Factors of Recwrrent Ckronic Subdurag Hematoma therapy \{Table (Table Neurol. Med. Chir. [Tokyo), 382-86, 2001.

19- SCOTTI G., TERBRUGGE K., MELANÇON D. and BÉLANGER G.: Evaluation of the age of subdural hematomas by computerized tomography. J. Neurosurg., 47: 311-5, 1977.

20- NORDMANN H.B.A. and GRATZL H.C.B.O.: Demographics and prevalent risk factors of chronic subdural haematoma: Results of a large single-center cohort study. Neurosurg. Rev., 27: 263-6, 2004.

21- STANISIC M. and MAHESPARAN R.: Clinical Article Treatment of chronic subdural hematoma by burr-hole craniostomy in adults: Influence of some factors on post- 
operative recurrence. Acta Neurochirugica, 147: 124957, 2005.

22- ABOUZARI M., et al.: The role of post-operative patient posture in the recurrence of traumatic chronic subdural hematoma after burr-hole surgery. Neurosurgery, 61: 7947, 2007.

23- WEIGEL R., HOHENSTEIN A., SCHLICKUM L., WEISS C. and SCHILLING L.: Angiotensin converting enzyme inhibition for arterial hypertension reduces the risk of recurrence in patients with chronic subdural hematoma possibly by an antiangiogenic mechanism. Neurosurgery, 61: 788-93, 2007.

24- GRØNBÆK H., et al.: Liver cirrhosis, other liver diseases, and risk of hospitalisation for intracerebral haemorrhage: A Danish population-based case-control study. B.M.C. Gastroenterol., 8: 16, 2008.

25- KAUL V.V. and MUNOZ S.J.: Coagulopathy of Liver Disease. Curr. Treat. Options Gastroenterol., 3: 433-8, 2000.

26- McCORMICK P.A. and MURPHY K.M.: Splenomegaly, hypersplenism and coagulation abnormalities in liver disease. Best Pract. Res. Clin. Gastroenterol., 14: 1009$31,2000$.

27- TUGCU B., et al.: Can Recurrent Chronic Subdural Hematomas Be Predicted? A Retrospective Analysis of 136 Cases. Dusunen Adam, 23: 44-9, 2010.

28- HUANG Y., LIN W., LU C. and CHEN W.: Volume of chronic subdural haematoma: Is it one of the radiographic factors related to recurrence? Injury, 45: 1327-31, 2014.

29- NAKAGUCHI H., TANISHIMA T. and YOSHIMASU N.: Relationship between drainage catheter location and post-operative recurrence of chronic subdural hematoma after burr-hole irrigation and closed-system drainage. J. Neurosurg., 93: 791-5, 2000.

30- HAMMER A., et al.: Predictors for Recurrence of Chronic Subdural Hematoma. Turk. Neurosurg., 1-7, 2016.

31- OH H.J., et al.: Post-operative course and recurrence of chronic subdural hematoma. J. Korean Neurosurg. Soc., 48: 518-23, 2010.

32- MARKWALDER T.M.: Chronic subdural hematomas: A review. J. Neurosurg., 54: 637-45, 1981.

33- MATSUMOTO K., et al.: Recurrence factors for chronic subdural hematomas after burr-hole craniostomy and closed system drainage. Neurol. Res., 21: 277-80, 1999.

34- CENIC A., BHANDARI M. and REDDY K.: Management of chronic subdural hematoma: A national survey and literature review. Can. J. Neurol. Sci. Can. Des. Sci. Neurol., 32: 501-6, 2005.

35- HAN H.J., et al.: One vs. two burr hole craniostomy in surgical treatment of chronic subdural hematoma. J. Korean Neurosurg. Soc., 46: 87-92, 2009.

36- KANSAL R., NADKARNI T. and GOEL A.: Single versus double burr hole drainage of chronic subdural hematomas. A study of 267 cases. J. Clin. Neurosci., 17: 428-9, 2010.

37- BELKHAIR S. and PICKETT G.: One Versus Double Burr Holes for Treating Chronic Subdural Hematoma Meta-Analysis. Can. J. Neurol. Sci., 40: 56-60, 2013.

38- TAUSSKY P., FANDINO J. and LANDOLT H.: Number of burr holes as independent predictor of post-operative recurrence in chronic subdural haematoma. Br. J. Neurosurg., 22: 279-82, 2008.

39- MARKWALDER T.M. and SEILER R.W.: Chronic Subdural Hematomas: To Drain or Not to Drain? Neurosurgery, 16: $185-8,1985$.

40- TSUTSUMI K., et al.: The relationship of pre-operative magnetic resonance imaging findings and closed system drainage in the recurrence of chronic subdural hematoma. J. Neurosurg., 87: 870-5, 1997.

41- WAKAI S., et al.: Efficacy of closed-system drainage in treating chronic subdural hematoma: A prospective comparative study. Neurosurgery, 26: 771-3, 1990.

42- BENZEL E.C., BRIDGES Jr., R.M. and ORRISON W.W.: The single burr hole technique for the evacuation of nonacute subdural hematomas. J. Trauma Acute Care Surg., 36: 190-4, 1994.

43- ROBINSON R.G.: Chronic subdural hematoma: Surgical management in 133 patients. J. Neurosurg., 61: 263-8, 1984.

44- KWAK Y.Y. and S. Frontal small craniostomy and irrigation for treatment of chronic subdural haematoma. Br. J. Neurosurg., 11: 150-1, 1997.

45- GAZZERI R., et al.: Continuous subgaleal suction drainage for the treatment of chronic subdural haematoma. Acta Neurochir. (Wien), 149: 487-93, 2007.

46- MOHAMED E.E.H.H.: Chronic subdural haematoma treated by craniotomy, durectomy, outer membranectomy and subgaleal suction drainage. Personal experience in 39 patients. Br. J. Neurosurg., 17: 244-7, 2003.

47- KWON T.H., et al.: Chronic subdural hematoma: Evaluation of the clinical significance of post-operative drainage volume. J. Neurosurg., 93: 796-9, 2000. 


\section{دراسة العوامل التى تسهم فى إرتجاع التجمع الدموى

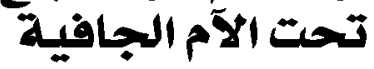

يعرف التجمع الدموى المزمن تحت الام الجافية بآنه تجمع غير طبيعى اللدم السائل تصت الآم الجافية وغالبا يتكن خلال ثلاثة آسابيع.

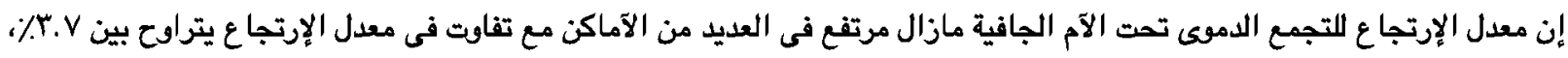

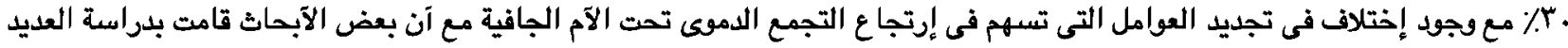

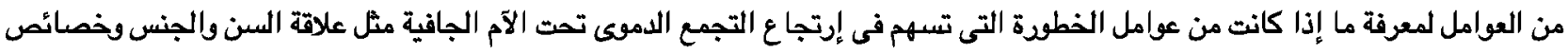

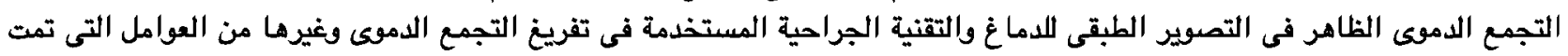
دراستها إلا آن الإتفاق عن إسهام هذه العوامل فى إرتجاع التجمع الدموى لازال محل خلاف.

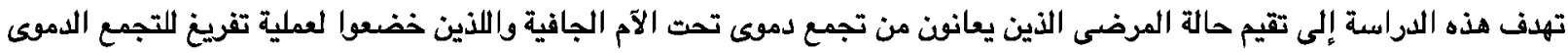

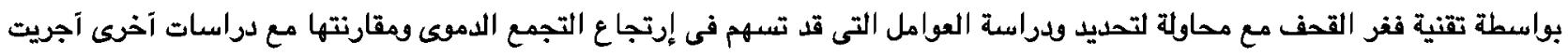

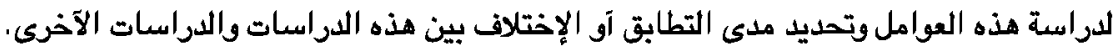

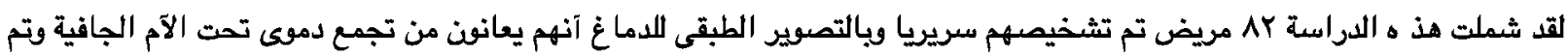

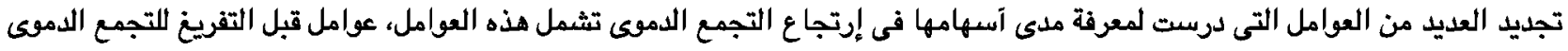

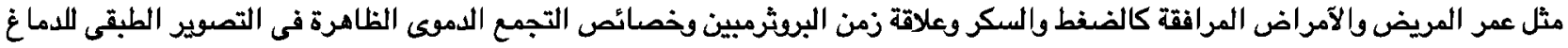

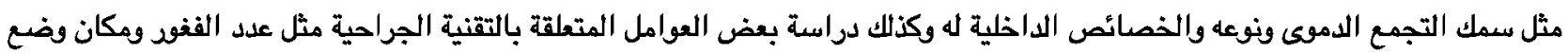

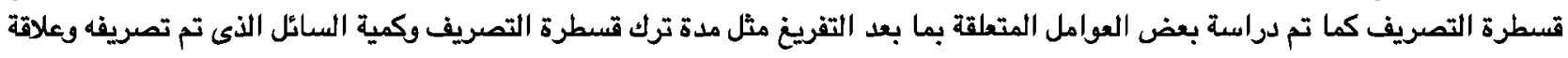
وجود بقايا تجمع دموى شبه صلب لم يتم تفريفه مع إرتجاع التجمع الدموى مرة آخرىى.

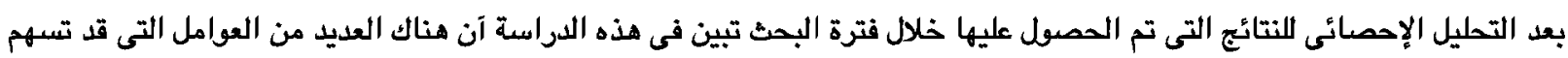

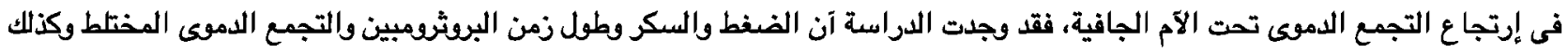

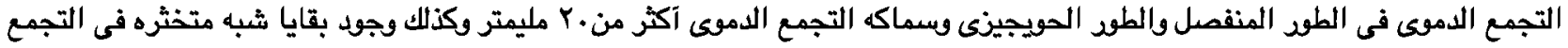

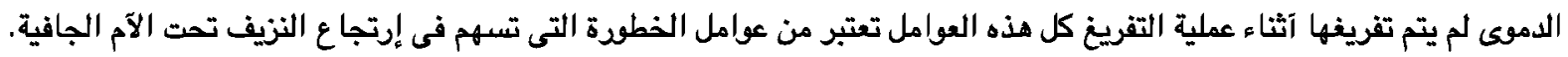

